\title{
Syntheses and Structures of Organic-Inorganic Hybrid Compounds Based on Metal-Fluconazole Coordination Polymers and $\beta-\mathrm{Mo}_{8} \mathrm{O}_{26}$ Anion
}

Shun-Li Li, Ya-Qian Lan, Jian-Fang Ma,* Jin Yang, Xiao-Hong Wang, Zhong-Min Su

\section{Supporting Information:}

Table S1. Selected bond distances $(\AA)$ and angles $\left({ }^{\circ}\right)$ for $\mathbf{1}$.

\begin{tabular}{|c|c|c|c|}
\hline $\mathrm{Co}(1)-\mathrm{O}(2 \mathrm{~W})$ & $2.101(2)$ & $\mathrm{Co}(1)-\mathrm{N}(7)$ & $2.126(2)$ \\
\hline $\mathrm{Co}(1)-\mathrm{N}(6) \# 1$ & $2.204(2)$ & $\operatorname{Co}(1)-\mathrm{N}(6)$ & $2.204(2)$ \\
\hline $\mathrm{Co}(2)-\mathrm{O}(1 \mathrm{~W})$ & $2.0838(19)$ & $\mathrm{Co}(2)-\mathrm{N}(12)$ & $2.1423(19)$ \\
\hline $\mathrm{Co}(2)-\mathrm{N}(1) \# 1$ & $2.175(2)$ & & \\
\hline $\mathrm{Mo}(1)-\mathrm{O}(4)$ & $1.690(2)$ & $\mathrm{Mo}(1)-\mathrm{O}(5)$ & $1.7002(19)$ \\
\hline $\mathrm{Mo}(1)-\mathrm{O}(6)$ & $1.9221(19)$ & $\mathrm{Mo}(1)-\mathrm{O}(3)$ & $1.9247(18)$ \\
\hline $\mathrm{Mo}(1)-\mathrm{O}(9)$ & $2.3557(18)$ & $\operatorname{Mo}(1)-\mathrm{O}(12)$ & $2.3761(16)$ \\
\hline $\mathrm{Mo}(2)-\mathrm{O}(13)$ & $1.691(2)$ & $\mathrm{Mo}(2)-\mathrm{O}(7)$ & $1.7016(19)$ \\
\hline $\mathrm{Mo}(2)-\mathrm{O}(6)$ & $1.8823(19)$ & $\operatorname{Mo}(2)-\mathrm{O}(10)$ & $1.9964(17)$ \\
\hline $\mathrm{Mo}(2)-\mathrm{O}(8)$ & $2.3496(16)$ & $\mathrm{Mo}(2)-\mathrm{O}(12)$ & $2.3687(16)$ \\
\hline $\mathrm{Mo}(3)-\mathrm{O}(11)$ & $1.6985(17)$ & $\mathrm{Mo}(3)-\mathrm{O}(9)$ & $1.7394(17)$ \\
\hline $\mathrm{Mo}(3)-\mathrm{O}(10) \# 4$ & $1.9403(16)$ & $\mathrm{Mo}(3)-\mathrm{O}(8)$ & $1.9484(16)$ \\
\hline $\mathrm{Mo}(3)-\mathrm{O}(12) \# 4$ & $2.1503(16)$ & $\mathrm{Mo}(3)-\mathrm{O}(12)$ & $2.3274(16)$ \\
\hline $\mathrm{Mo}(4)-\mathrm{O}(1)$ & $1.6961(19)$ & $\mathrm{Mo}(4)-\mathrm{O}(2)$ & $1.7110(18)$ \\
\hline $\mathrm{Mo}(4)-\mathrm{O}(3)$ & $1.8706(18)$ & $\mathrm{Mo}(4)-\mathrm{O}(8) \# 4$ & $1.9873(16)$ \\
\hline $\mathrm{Mo}(4)-\mathrm{O}(10) \# 4$ & $2.3386(17)$ & $\mathrm{Mo}(4)-\mathrm{O}(12)$ & $2.3455(16)$ \\
\hline $\mathrm{O}(8)-\mathrm{Mo}(4) \# 4$ & $1.9873(16)$ & $\mathrm{O}(10)-\mathrm{Mo}(3) \# 4$ & $1.9403(16)$ \\
\hline $\mathrm{O}(10)-\mathrm{Mo}(4) \# 4$ & $2.3386(17)$ & $\mathrm{O}(12)-\mathrm{Mo}(3) \# 4$ & $2.1503(16)$ \\
\hline $\mathrm{O}(2 \mathrm{~W}) \# 1-\mathrm{Co}(1)$ & $90.01(8)$ & $\mathrm{O}(2 \mathrm{~W})-\mathrm{Co}(1)-\mathrm{N}(7)$ & $89.99(8)$ \\
\hline
\end{tabular}




\begin{tabular}{|c|c|c|c|}
\hline $\mathrm{O}(2 \mathrm{~W}) \# 1-\mathrm{Co}(1)-\mathrm{N}(6) \# 1$ & $89.29(8)$ & $\mathrm{O}(2 \mathrm{~W})-\mathrm{Co}(1)-\mathrm{N}(6) \# 1$ & $90.71(8)$ \\
\hline $\mathrm{N}(7)-\mathrm{Co}(1)-\mathrm{N}(6) \# 1$ & $89.02(8)$ & $\mathrm{N}(7) \# 1-\mathrm{Co}(1)-\mathrm{N}(6) \# 1$ & $90.98(8)$ \\
\hline $\mathrm{O}(2 \mathrm{~W}) \# 1-\mathrm{Co}(1)-\mathrm{N}(6)$ & $90.71(8)$ & $\mathrm{O}(2 \mathrm{~W})-\mathrm{Co}(1)-\mathrm{N}(6)$ & $89.29(8)$ \\
\hline $\mathrm{N}(7)-\mathrm{Co}(1)-\mathrm{N}(6)$ & $90.98(8)$ & $\mathrm{N}(7) \# 1-\mathrm{Co}(1)-\mathrm{N}(6)$ & $89.02(8)$ \\
\hline $\mathrm{O}(1 \mathrm{~W}) \# 2-\mathrm{Co}(2)-\mathrm{N}(12) \# 2$ & $89.60(8)$ & $\mathrm{O}(1 \mathrm{~W})-\mathrm{Co}(2)-\mathrm{N}(12) \# 2$ & $90.40(8)$ \\
\hline $\mathrm{O}(1 \mathrm{~W}) \# 2-\mathrm{Co}(2)-\mathrm{N}(12)$ & $90.40(8)$ & $\mathrm{O}(1 \mathrm{~W})-\mathrm{Co}(2)-\mathrm{N}(12)$ & $89.60(8)$ \\
\hline $\mathrm{N}(12) \# 2-\mathrm{Co}(2)-\mathrm{N}(12)$ & 180.0 & $\mathrm{O}(1 \mathrm{~W}) \# 2-\mathrm{Co}(2)-\mathrm{N}(1) \# 1$ & $85.23(8)$ \\
\hline $\mathrm{O}(1 \mathrm{~W})-\mathrm{Co}(2)-\mathrm{N}(1) \# 1$ & $94.77(8)$ & $\mathrm{N}(12) \# 2-\mathrm{Co}(2)-\mathrm{N}(1) \# 1$ & $86.61(7)$ \\
\hline $\mathrm{N}(12)-\mathrm{Co}(2)-\mathrm{N}(1) \# 1$ & $93.39(7)$ & $\mathrm{O}(1 \mathrm{~W}) \# 2-\mathrm{Co}(2)-\mathrm{N}(1) \# 3$ & $94.77(8)$ \\
\hline $\mathrm{O}(1 \mathrm{~W})-\mathrm{Co}(2)-\mathrm{N}(1) \# 3$ & $85.23(8)$ & $\mathrm{N}(12) \# 2-\mathrm{Co}(2)-\mathrm{N}(1) \# 3$ & $93.39(7)$ \\
\hline $\mathrm{N}(12)-\mathrm{Co}(2)-\mathrm{N}(1) \# 3$ & $86.61(7)$ & $\mathrm{N}(1) \# 1-\mathrm{Co}(2)-\mathrm{N}(1) \# 3$ & 180.0 \\
\hline $\mathrm{O}(4)-\mathrm{Mo}(1)-\mathrm{O}(5)$ & $106.08(10)$ & $\mathrm{O}(4)-\mathrm{Mo}(1)-\mathrm{O}(6)$ & $99.75(10)$ \\
\hline $\mathrm{O}(5)-\mathrm{Mo}(1)-\mathrm{O}(6)$ & $102.07(10)$ & $\mathrm{O}(4)-\mathrm{Mo}(1)-\mathrm{O}(3)$ & $98.81(9)$ \\
\hline $\mathrm{O}(5)-\mathrm{Mo}(1)-\mathrm{O}(3)$ & $100.86(10)$ & $\mathrm{O}(6)-\mathrm{Mo}(1)-\mathrm{O}(3)$ & $145.04(7)$ \\
\hline $\mathrm{O}(4)-\mathrm{Mo}(1)-\mathrm{O}(9)$ & $163.07(8)$ & $\mathrm{O}(5)-\mathrm{Mo}(1)-\mathrm{O}(9)$ & $90.84(8)$ \\
\hline $\mathrm{O}(6)-\mathrm{Mo}(1)-\mathrm{O}(9)$ & $76.92(7)$ & $\mathrm{O}(3)-\mathrm{Mo}(1)-\mathrm{O}(9)$ & $76.72(7)$ \\
\hline $\mathrm{O}(4)-\mathrm{Mo}(1)-\mathrm{O}(12)$ & $93.23(8)$ & $\mathrm{O}(5)-\mathrm{Mo}(1)-\mathrm{O}(12)$ & $160.66(9)$ \\
\hline $\mathrm{O}(6)-\mathrm{Mo}(1)-\mathrm{O}(12)$ & $75.07(6)$ & $\mathrm{O}(3)-\mathrm{Mo}(1)-\mathrm{O}(12)$ & $74.54(6)$ \\
\hline $\mathrm{O}(9)-\mathrm{Mo}(1)-\mathrm{O}(12)$ & $69.84(6)$ & $\mathrm{O}(13)-\mathrm{Mo}(2)-\mathrm{O}(7)$ & $105.55(10)$ \\
\hline $\mathrm{O}(13)-\mathrm{Mo}(2)-\mathrm{O}(6)$ & $102.90(10)$ & $\mathrm{O}(7)-\mathrm{Mo}(2)-\mathrm{O}(6)$ & $101.84(9)$ \\
\hline $\mathrm{O}(13)-\mathrm{Mo}(2)-\mathrm{O}(10)$ & $100.63(9)$ & $\mathrm{O}(7)-\mathrm{Mo}(2)-\mathrm{O}(10)$ & $96.95(9)$ \\
\hline $\mathrm{O}(6)-\mathrm{Mo}(2)-\mathrm{O}(10)$ & $144.51(7)$ & $\mathrm{O}(13)-\mathrm{Mo}(2)-\mathrm{O}(8)$ & $88.49(8)$ \\
\hline $\mathrm{O}(7)-\mathrm{Mo}(2)-\mathrm{O}(8)$ & $163.29(8)$ & $\mathrm{O}(6)-\mathrm{Mo}(2)-\mathrm{O}(8)$ & $83.32(7)$ \\
\hline
\end{tabular}




\begin{tabular}{|c|c|c|c|}
\hline $\mathrm{O}(10)-\mathrm{Mo}(2)-\mathrm{O}(8)$ & $71.09(6)$ & $\mathrm{O}(13)-\mathrm{Mo}(2)-\mathrm{O}(12)$ & $158.79(8)$ \\
\hline $\mathrm{O}(7)-\mathrm{Mo}(2)-\mathrm{O}(12)$ & $95.31(8)$ & $\mathrm{O}(6)-\mathrm{Mo}(2)-\mathrm{O}(12)$ & $75.94(7)$ \\
\hline $\mathrm{O}(10)-\mathrm{Mo}(2)-\mathrm{O}(12)$ & $72.55(6)$ & $\mathrm{O}(8)-\mathrm{Mo}(2)-\mathrm{O}(12)$ & $70.31(6)$ \\
\hline $\mathrm{O}(11)-\mathrm{Mo}(3)-\mathrm{O}(9)$ & 105.38(9) & $\mathrm{O}(11)-\mathrm{Mo}(3)-\mathrm{O}(10) \# 4$ & $101.13(8)$ \\
\hline $\mathrm{O}(9)-\mathrm{Mo}(3)-\mathrm{O}(10) \# 4$ & $97.28(8)$ & $\mathrm{O}(11)-\mathrm{Mo}(3)-\mathrm{O}(8)$ & $99.96(8)$ \\
\hline $\mathrm{O}(9)-\mathrm{Mo}(3)-\mathrm{O}(8)$ & $96.79(8)$ & $\mathrm{O}(10) \# 4-\mathrm{Mo}(3)-\mathrm{O}(8)$ & $150.46(7)$ \\
\hline $\mathrm{O}(11)-\mathrm{Mo}(3)-\mathrm{O}(12) \# 4$ & $96.63(8)$ & $\mathrm{O}(9)-\mathrm{Mo}(3)-\mathrm{O}(12) \# 4$ & $157.98(7)$ \\
\hline $\mathrm{O}(10) \# 4-\mathrm{Mo}(3)-\mathrm{O}(12) \# 4$ & $78.74(7)$ & $\mathrm{O}(8)-\mathrm{Mo}(3)-\mathrm{O}(12) \# 4$ & $78.48(6)$ \\
\hline $\mathrm{O}(11)-\mathrm{Mo}(3)-\mathrm{O}(12)$ & $172.45(7)$ & $\mathrm{O}(9)-\mathrm{Mo}(3)-\mathrm{O}(12)$ & $82.15(7)$ \\
\hline $\mathrm{O}(10) \# 4-\mathrm{Mo}(3)-\mathrm{O}(12)$ & $78.03(6)$ & $\mathrm{O}(8)-\mathrm{Mo}(3)-\mathrm{O}(12)$ & $78.35(6)$ \\
\hline $\mathrm{O}(12) \# 4-\mathrm{Mo}(3)-\mathrm{O}(12)$ & $75.83(6)$ & $\mathrm{O}(1)-\mathrm{Mo}(4)-\mathrm{O}(2)$ & $104.92(10)$ \\
\hline $\mathrm{O}(1)-\mathrm{Mo}(4)-\mathrm{O}(3)$ & $101.28(9)$ & $\mathrm{O}(2)-\mathrm{Mo}(4)-\mathrm{O}(3)$ & $101.93(9)$ \\
\hline $\mathrm{O}(1)-\mathrm{Mo}(4)-\mathrm{O}(8) \# 4$ & 101.61(9) & $\mathrm{O}(2)-\mathrm{Mo}(4)-\mathrm{O}(8) \# 4$ & $97.21(8)$ \\
\hline $\mathrm{O}(3)-\mathrm{Mo}(4)-\mathrm{O}(8) \# 4$ & $145.09(7)$ & $\mathrm{O}(1)-\mathrm{Mo}(4)-\mathrm{O}(10) \# 4$ & $89.17(8)$ \\
\hline $\mathrm{O}(2)-\mathrm{Mo}(4)-\mathrm{O}(10) \# 4$ & $163.69(7)$ & $\mathrm{O}(3)-\mathrm{Mo}(4)-\mathrm{O}(10) \# 4$ & $82.87(7)$ \\
\hline $\mathrm{O}(8) \# 4-\mathrm{Mo}(4)-\mathrm{O}(10) \# 4$ & $71.48(6)$ & $\mathrm{O}(1)-\mathrm{Mo}(4)-\mathrm{O}(12)$ & $159.66(8)$ \\
\hline $\mathrm{O}(2)-\mathrm{Mo}(4)-\mathrm{O}(12)$ & $95.30(7)$ & $\mathrm{O}(3)-\mathrm{Mo}(4)-\mathrm{O}(12)$ & $76.23(7)$ \\
\hline $\mathrm{O}(8) \# 4-\mathrm{Mo}(4)-\mathrm{O}(12)$ & $73.14(6)$ & $\mathrm{O}(10) \# 4-\mathrm{Mo}(4)-\mathrm{O}(12)$ & $70.50(6)$ \\
\hline
\end{tabular}

Symmetry codes for 1 : \#1-x, -y, -z; \#2-x+1, -y+1, -z+1; \#3x+1, y+1, z+1; \#4-x+2, -y, -z+1; $\# 5 \mathrm{x}-1, \mathrm{y}-1, \mathrm{z}-1$

Table S2. Selected bond distances $(\AA)$ and angles $\left({ }^{\circ}\right)$ for $\mathbf{2}$.

\begin{tabular}{llll}
\hline $\mathrm{Ni}(1)-\mathrm{O}(1 \mathrm{~W})$ & $2.0760(18)$ & $\mathrm{Ni}(1)-\mathrm{N}(3)$ & $2.0956(18)$ \\
$\mathrm{Ni}(1)-\mathrm{N}(9)$ & $2.1156(19)$ & $\mathrm{Ni}(2)-\mathrm{N}(6)$ & $2.0800(19)$
\end{tabular}




\begin{tabular}{|c|c|c|c|}
\hline $\mathrm{Ni}(2)-\mathrm{O}(2 \mathrm{~W})$ & $2.0857(19)$ & Ni(2)-N(10) & $2.148(2)$ \\
\hline $\mathrm{Mo}(1)-\mathrm{O}(6)$ & $1.6997(17)$ & $\mathrm{Mo}(1)-\mathrm{O}(5)$ & $1.7424(17)$ \\
\hline $\mathrm{Mo}(1)-\mathrm{O}(8)$ & $1.9398(16)$ & $\mathrm{Mo}(1)-\mathrm{O}(7)$ & $1.9478(17)$ \\
\hline $\mathrm{Mo}(1)-\mathrm{O}(9) \# 3$ & $2.1522(17)$ & $\mathrm{Mo}(1)-\mathrm{O}(9)$ & $2.3287(15)$ \\
\hline $\mathrm{Mo}(2)-\mathrm{O}(2)$ & $1.6913(19)$ & $\mathrm{Mo}(2)-\mathrm{O}(1)$ & $1.6992(19)$ \\
\hline $\mathrm{Mo}(2)-\mathrm{O}(4)$ & $1.9209(19)$ & $\mathrm{Mo}(2)-\mathrm{O}(3)$ & $1.9249(19)$ \\
\hline $\mathrm{Mo}(2)-\mathrm{O}(5)$ & $2.3625(17)$ & $\mathrm{Mo}(2)-\mathrm{O}(9)$ & $2.3760(17)$ \\
\hline $\mathrm{Mo}(3)-\mathrm{O}(10)$ & $1.6883(19)$ & $\mathrm{Mo}(3)-\mathrm{O}(11)$ & $1.7013(18)$ \\
\hline $\mathrm{Mo}(3)-\mathrm{O}(4)$ & $1.8818(19)$ & $\mathrm{Mo}(3)-\mathrm{O}(8) \# 3$ & $2.0004(18)$ \\
\hline $\mathrm{Mo}(3)-\mathrm{O}(7)$ & $2.3488(17)$ & $\mathrm{Mo}(3)-\mathrm{O}(9)$ & $2.3679(17)$ \\
\hline $\mathrm{Mo}(4)-\mathrm{O}(12)$ & $1.6962(19)$ & $\mathrm{Mo}(4)-\mathrm{O}(13)$ & $1.7129(18)$ \\
\hline $\mathrm{Mo}(4)-\mathrm{O}(3)$ & $1.8719(19)$ & $\mathrm{Mo}(4)-\mathrm{O}(7) \# 3$ & $1.9900(17)$ \\
\hline $\mathrm{Mo}(4)-\mathrm{O}(8)$ & $2.3383(16)$ & $\mathrm{Mo}(4)-\mathrm{O}(9)$ & $2.3467(16)$ \\
\hline $\mathrm{O}(7)-\mathrm{Mo}(4) \# 3$ & $1.9900(17)$ & $\mathrm{O}(8)-\mathrm{Mo}(3) \# 3$ & $2.0004(18)$ \\
\hline $\mathrm{O}(9)-\mathrm{Mo}(1) \# 3$ & $2.1522(17)$ & & \\
\hline $\mathrm{O}(1 \mathrm{~W})-\mathrm{Ni}(1)-\mathrm{N}(3) \# 1$ & $90.88(8)$ & $\mathrm{O}(1 \mathrm{~W})-\mathrm{Ni}(1)-\mathrm{N}(3)$ & $89.12(8)$ \\
\hline $\mathrm{O}(1 \mathrm{~W}) \# 1-\mathrm{Ni}(1)-\mathrm{N}(3)$ & $90.88(8)$ & $\mathrm{O}(1 \mathrm{~W})-\mathrm{Ni}(1)-\mathrm{N}(9) \# 1$ & $93.69(9)$ \\
\hline $\mathrm{N}(3)-\mathrm{Ni}(1)-\mathrm{N}(9) \# 1$ & $92.55(8)$ & $\mathrm{O}(1 \mathrm{~W})-\mathrm{Ni}(1)-\mathrm{N}(9)$ & $86.31(9)$ \\
\hline N(3)-Ni(1)-N(9) & $87.45(8)$ & $\mathrm{N}(6)-\mathrm{Ni}(2)-\mathrm{O}(2 \mathrm{~W}) \# 2$ & $90.22(8)$ \\
\hline $\mathrm{N}(6)-\mathrm{Ni}(2)-\mathrm{O}(2 \mathrm{~W})$ & $89.78(8)$ & $\mathrm{N}(6)-\mathrm{Ni}(2)-\mathrm{N}(10)$ & $89.86(9)$ \\
\hline $\mathrm{O}(2 \mathrm{~W}) \# 2-\mathrm{Ni}(2)-\mathrm{N}(10)$ & $91.62(8)$ & $\mathrm{O}(2 \mathrm{~W})-\mathrm{Ni}(2)-\mathrm{N}(10)$ & $88.38(8)$ \\
\hline $\mathrm{N}(6)-\mathrm{Ni}(2)-\mathrm{N}(10) \# 2$ & $90.14(9)$ & $\mathrm{O}(8)-\mathrm{Mo}(4)-\mathrm{O}(9)$ & $70.46(6)$ \\
\hline $\mathrm{O}(6)-\mathrm{Mo}(1)-\mathrm{O}(5)$ & $105.39(8)$ & $\mathrm{O}(6)-\mathrm{Mo}(1)-\mathrm{O}(8)$ & $100.95(8)$ \\
\hline $\mathrm{O}(5)-\mathrm{Mo}(1)-\mathrm{O}(8)$ & $97.18(8)$ & $\mathrm{O}(6)-\mathrm{Mo}(1)-\mathrm{O}(7)$ & $100.16(8)$ \\
\hline $\mathrm{O}(5)-\mathrm{Mo}(1)-\mathrm{O}(7)$ & $96.87(8)$ & $\mathrm{O}(8)-\mathrm{Mo}(1)-\mathrm{O}(7)$ & $150.47(7)$ \\
\hline $\mathrm{O}(6)-\mathrm{Mo}(1)-\mathrm{O}(9) \# 3$ & $96.48(7)$ & $\mathrm{O}(5)-\mathrm{Mo}(1)-\mathrm{O}(9) \# 3$ & $158.13(7)$ \\
\hline $\mathrm{O}(8)-\mathrm{Mo}(1)-\mathrm{O}(9) \# 3$ & $78.75(7)$ & $\mathrm{O}(7)-\mathrm{Mo}(1)-\mathrm{O}(9) \# 3$ & $78.56(6)$ \\
\hline $\mathrm{O}(6)-\mathrm{Mo}(1)-\mathrm{O}(9)$ & $172.37(7)$ & $\mathrm{O}(5)-\mathrm{Mo}(1)-\mathrm{O}(9)$ & $82.24(7)$ \\
\hline $\mathrm{O}(8)-\mathrm{Mo}(1)-\mathrm{O}(9)$ & $77.98(7)$ & $\mathrm{O}(7)-\mathrm{Mo}(1)-\mathrm{O}(9)$ & $78.36(6)$ \\
\hline
\end{tabular}




\begin{tabular}{lrlr}
$\mathrm{O}(9) \# 3-\mathrm{Mo}(1)-\mathrm{O}(9)$ & $75.90(6)$ & $\mathrm{O}(2)-\mathrm{Mo}(2)-\mathrm{O}(1)$ & $105.97(10)$ \\
$\mathrm{O}(2)-\mathrm{Mo}(2)-\mathrm{O}(4)$ & $99.94(9)$ & $\mathrm{O}(1)-\mathrm{Mo}(2)-\mathrm{O}(4)$ & $102.01(9)$ \\
$\mathrm{O}(2)-\mathrm{Mo}(2)-\mathrm{O}(3)$ & $98.64(9)$ & $\mathrm{O}(1)-\mathrm{Mo}(2)-\mathrm{O}(3)$ & $100.97(10)$ \\
$\mathrm{O}(4)-\mathrm{Mo}(2)-\mathrm{O}(3)$ & $145.02(7)$ & $\mathrm{O}(2)-\mathrm{Mo}(2)-\mathrm{O}(5)$ & $163.01(8)$ \\
$\mathrm{O}(1)-\mathrm{Mo}(2)-\mathrm{O}(5)$ & $90.99(8)$ & $\mathrm{O}(4)-\mathrm{Mo}(2)-\mathrm{O}(5)$ & $76.95(7)$ \\
$\mathrm{O}(3)-\mathrm{Mo}(2)-\mathrm{O}(5)$ & $76.64(7)$ & $\mathrm{O}(2)-\mathrm{Mo}(2)-\mathrm{O}(9)$ & $93.16(8)$ \\
$\mathrm{O}(1)-\mathrm{Mo}(2)-\mathrm{O}(9)$ & $160.85(8)$ & $\mathrm{O}(4)-\mathrm{Mo}(2)-\mathrm{O}(9)$ & $75.02(6)$ \\
$\mathrm{O}(3)-\mathrm{Mo}(2)-\mathrm{O}(9)$ & $74.61(6)$ & $\mathrm{O}(5)-\mathrm{Mo}(2)-\mathrm{O}(9)$ & $69.87(5)$ \\
$\mathrm{O}(10)-\mathrm{Mo}(3)-\mathrm{O}(11)$ & $105.62(10)$ & $\mathrm{O}(10)-\mathrm{Mo}(3)-\mathrm{O}(4)$ & $102.92(10)$ \\
$\mathrm{O}(11)-\mathrm{Mo}(3)-\mathrm{O}(4)$ & $101.91(9)$ & $\mathrm{O}(10)-\mathrm{Mo}(3)-\mathrm{O}(8) \# 3$ & $100.69(9)$ \\
$\mathrm{O}(11)-\mathrm{Mo}(3)-\mathrm{O}(8) \# 3$ & $96.73(8)$ & $\mathrm{O}(4)-\mathrm{Mo}(3)-\mathrm{O}(8) \# 3$ & $144.53(7)$ \\
$\mathrm{O}(10)-\mathrm{Mo}(3)-\mathrm{O}(7)$ & $88.36(8)$ & $\mathrm{O}(11)-\mathrm{Mo}(3)-\mathrm{O}(7)$ & $163.21(7)$ \\
$\mathrm{O}(4)-\mathrm{Mo}(3)-\mathrm{O}(7)$ & $83.48(7)$ & $\mathrm{O}(8) \# 3-\mathrm{Mo}(3)-\mathrm{O}(7)$ & $71.09(6)$ \\
$\mathrm{O}(10)-\mathrm{Mo}(3)-\mathrm{O}(9)$ & $158.72(8)$ & $\mathrm{O}(11)-\mathrm{Mo}(3)-\mathrm{O}(9)$ & $95.31(8)$ \\
$\mathrm{O}(4)-\mathrm{Mo}(3)-\mathrm{O}(9)$ & $75.89(7)$ & $\mathrm{O}(8) \# 3-\mathrm{Mo}(3)-\mathrm{O}(9)$ & $72.53(6)$ \\
$\mathrm{O}(7)-\mathrm{Mo}(3)-\mathrm{O}(9)$ & $70.36(6)$ & $\mathrm{O}(12)-\mathrm{Mo}(4)-\mathrm{O}(13)$ & $104.87(9)$ \\
$\mathrm{O}(12)-\mathrm{Mo}(4)-\mathrm{O}(3)$ & $101.23(9)$ & $\mathrm{O}(13)-\mathrm{Mo}(4)-\mathrm{O}(3)$ & $101.67(8)$ \\
$\mathrm{O}(12)-\mathrm{Mo}(4)-\mathrm{O}(7) \# 3$ & $101.67(8)$ & $\mathrm{O}(13)-\mathrm{Mo}(4)-\mathrm{O}(7) \# 3$ & $97.42(8)$ \\
$\mathrm{O}(3)-\mathrm{Mo}(4)-\mathrm{O}(7) \# 3$ & $145.13(7)$ & $\mathrm{O}(12)-\mathrm{Mo}(4)-\mathrm{O}(8)$ & $89.35(8)$ \\
$\mathrm{O}(13)-\mathrm{Mo}(4)-\mathrm{O}(8)$ & $163.72(7)$ & $\mathrm{O}(3)-\mathrm{Mo}(4)-\mathrm{O}(8)$ & $82.86(7)$ \\
$\mathrm{O}(7) \# 3-\mathrm{Mo}(4)-\mathrm{O}(8)$ & $71.49(6)$ & $\mathrm{O}(12)-\mathrm{Mo}(4)-\mathrm{O}(9)$ & $159.80(8)$ \\
$\mathrm{O}(13)-\mathrm{Mo}(4)-\mathrm{O}(9)$ & $95.22(7)$ & $\mathrm{O}(3)-\mathrm{Mo}(4)-\mathrm{O}(9)$ & $76.25(6)$ \\
$\mathrm{O}(7) \# 3-\mathrm{Mo}(4)-\mathrm{O}(9)$ & $73.17(6)$ & & \\
\hline & & & \\
\hline & & & \\
\hline & & & \\
\hline & & & \\
\hline
\end{tabular}

Symmetry codes for 2 : \#1-x, -y, -z; \#2-x+1, -y+1, -z+1; \#3-x+1, -y+1, -z; \#4x+1, y+1, z+1; $\# 5 \mathrm{x}-1, \mathrm{y}-1, \mathrm{z}-1$

Table S3. Selected bond distances $(\AA)$ and angles $\left({ }^{\circ}\right)$ for $\mathbf{3}$.

\begin{tabular}{llll}
\hline $\mathrm{Zn}(1)-\mathrm{N}(1) \# 1 \quad \mathrm{Zn}(1)-\mathrm{N}(4)$ & 2.078(2)
\end{tabular}




\begin{tabular}{|c|c|c|c|}
\hline $\mathrm{Zn}(1)-\mathrm{N}(7)$ & $2.004(2)$ & $\mathrm{Zn}(1)-\mathrm{N}(11)$ & $2.208(2)$ \\
\hline $\mathrm{Zn}(1)-\mathrm{O}(12)$ & $2.4589(19)$ & $\mathrm{Mo}(2)-\mathrm{O}(7)$ & $1.698(2)$ \\
\hline $\mathrm{Mo}(2)-\mathrm{O}(9)$ & $1.703(2)$ & $\mathrm{Mo}(2)-\mathrm{O}(5)$ & $9040(19)$ \\
\hline $\mathrm{Mo}(2)-\mathrm{O}(11)$ & $1.9480(18)$ & $\mathrm{Mo}(2)-\mathrm{O}(6)$ & $2969(18)$ \\
\hline $\mathrm{Mo}(2)-\mathrm{O}(4)$ & $2.4028(17)$ & $\mathrm{Mo}(1)-\mathrm{O}(1)$ & $1.692(2)$ \\
\hline $\mathrm{Mo}(1)-\mathrm{O}(5)$ & $1.8958(19)$ & $\mathrm{Mo}(4)-\mathrm{O}(8)$ & $2.3548(17)$ \\
\hline $\mathrm{Mo}(1)-\mathrm{O}(8) \# 2$ & $1.9855(18)$ & $\mathrm{Mo}(1)-\mathrm{O}(4)$ & $3983(17)$ \\
\hline $\mathrm{Mo}(1)-\mathrm{O}(10) \# 2$ & $2.4102(18)$ & $\operatorname{Mo}(1)-\operatorname{Mo}(3)$ & $3.2187(3)$ \\
\hline $\mathrm{Mo}(3)-\mathrm{O}(3)$ & 1.6823(19) & $\mathrm{Mo}(3)-\mathrm{O}(6) \# 2$ & $1.7529(18)$ \\
\hline $\mathrm{Mo}(3)-\mathrm{O}(8) \# 2$ & $1.9428(18)$ & $\operatorname{Mo}(3)-\mathrm{O}(10)$ & $1.9612(18)$ \\
\hline $\mathrm{Mo}(3)-\mathrm{O}(4)$ & $2.1240(17)$ & $\mathrm{Mo}(3)-\mathrm{O}(4) \# 2$ & $2.3961(17)$ \\
\hline $\operatorname{Mo}(3)-\operatorname{Mo}(4)$ & $3.2059(3)$ & $\mathrm{Mo}(4)-\mathrm{O}(13)$ & $1.6942(19)$ \\
\hline $\mathrm{Mo}(4)-\mathrm{O}(12)$ & $1.7214(18)$ & $\mathrm{Mo}(4)-\mathrm{O}(11)$ & $1.9038(18)$ \\
\hline $\mathrm{Mo}(4)-\mathrm{O}(10)$ & $1.9648(18)$ & $\mathrm{Mo}(4)-\mathrm{O}(4)$ & $2.3244(17)$ \\
\hline $\mathrm{Mo}(1)-\mathrm{O}(2)$ & $1.690(2)$ & $\mathrm{Mo}(2)-\mathrm{O}(7)$ & $1.698(2)$ \\
\hline $\mathrm{N}(1) \# 1-\mathrm{Zn}(1)-\mathrm{N}(4)$ & $122.30(9)$ & N(1)\#1-Zn(1)-N(7) & $121.59(10)$ \\
\hline $\mathrm{N}(4)-\mathrm{Zn}(1)-\mathrm{N}(7)$ & $114.41(10)$ & $\mathrm{N}(1) \# 1-\mathrm{Zn}(1)-\mathrm{N}(11)$ & $98.46(8)$ \\
\hline $\mathrm{N}(7)-\mathrm{Zn}(1)-\mathrm{N}(11)$ & $95.01(9)$ & $\mathrm{N}(1) \# 1-\mathrm{Zn}(1)-\mathrm{O}(12)$ & $87.30(8)$ \\
\hline $\mathrm{N}(4)-\mathrm{Zn}(1)-\mathrm{O}(12)$ & $82.62(8)$ & $\mathrm{N}(7)-\mathrm{Zn}(1)-\mathrm{O}(12)$ & $87.00(8)$ \\
\hline $\mathrm{N}(11)-\mathrm{Zn}(1)-\mathrm{O}(12)$ & $171.67(7)$ & $\mathrm{O}(7)-\mathrm{Mo}(2)-\mathrm{O}(9)$ & $105.88(11)$ \\
\hline $\mathrm{O}(7)-\mathrm{Mo}(2)-\mathrm{O}(5)$ & $103.52(9)$ & $\mathrm{O}(9)-\mathrm{Mo}(2)-\mathrm{O}(5)$ & $99.71(9)$ \\
\hline $\mathrm{O}(7)-\mathrm{Mo}(2)-\mathrm{O}(11)$ & $99.64(9)$ & $\mathrm{O}(9)-\mathrm{Mo}(2)-\mathrm{O}(11)$ & $98.34(9)$ \\
\hline $\mathrm{O}(5)-\mathrm{Mo}(2)-\mathrm{O}(11)$ & $145.32(8)$ & $\mathrm{O}(7)-\mathrm{Mo}(2)-\mathrm{O}(6)$ & $88.66(9)$ \\
\hline $\mathrm{O}(9)-\mathrm{Mo}(2)-\mathrm{O}(6)$ & $165.36(9)$ & $\mathrm{O}(5)-\mathrm{Mo}(2)-\mathrm{O}(6)$ & $77.98(8)$ \\
\hline $\mathrm{O}(11)-\mathrm{Mo}(2)-\mathrm{O}(6)$ & $77.11(7)$ & $\mathrm{O}(7)-\mathrm{Mo}(2)-\mathrm{O}(4)$ & $159.03(9)$ \\
\hline $\mathrm{O}(9)-\mathrm{Mo}(2)-\mathrm{O}(4)$ & $94.86(8)$ & $\mathrm{O}(5)-\mathrm{Mo}(2)-\mathrm{O}(4)$ & $75.29(7)$ \\
\hline $\mathrm{O}(11)-\mathrm{Mo}(2)-\mathrm{O}(4)$ & $73.87(7)$ & $\mathrm{O}(6)-\mathrm{Mo}(2)-\mathrm{O}(4)$ & $70.53(6)$ \\
\hline $\mathrm{O}(2)-\mathrm{Mo}(1)-\mathrm{O}(1)$ & $105.78(11)$ & $\mathrm{O}(2)-\mathrm{Mo}(1)-\mathrm{O}(5)$ & $101.62(10)$ \\
\hline $\mathrm{O}(1)-\mathrm{Mo}(1)-\mathrm{O}(5)$ & $102.09(10)$ & $\mathrm{O}(2)-\mathrm{Mo}(1)-\mathrm{O}(8) \# 2$ & $98.50(9)$ \\
\hline
\end{tabular}




\begin{tabular}{|c|c|c|c|}
\hline $\mathrm{O}(1)-\mathrm{Mo}(1)-\mathrm{O}(8) \# 2$ & $102.03(9)$ & $\mathrm{O}(5)-\mathrm{Mo}(1)-\mathrm{O}(8) \# 2$ & $142.84(8)$ \\
\hline $\mathrm{O}(2)-\mathrm{Mo}(1)-\mathrm{O}(4)$ & $93.80(9)$ & $\mathrm{O}(1)-\mathrm{Mo}(1)-\mathrm{O}(4)$ & $160.30(9)$ \\
\hline $\mathrm{O}(5)-\mathrm{Mo}(1)-\mathrm{O}(4)$ & $75.55(7)$ & $\mathrm{O}(8) \# 2-\mathrm{Mo}(1)-\mathrm{O}(4)$ & $72.22(7)$ \\
\hline $\mathrm{O}(2)-\mathrm{Mo}(1)-\mathrm{O}(10) \# 2$ & $162.96(9)$ & $\mathrm{O}(1)-\mathrm{Mo}(1)-\mathrm{O}(10) \# 2$ & $89.65(9)$ \\
\hline $\mathrm{O}(5)-\mathrm{Mo}(1)-\mathrm{O}(10) \# 2$ & $81.68(7)$ & $\mathrm{O}(8) \# 2-\mathrm{Mo}(1)-\mathrm{O}(10) \# 2$ & $70.64(6)$ \\
\hline $\mathrm{O}(4)-\mathrm{Mo}(1)-\mathrm{O}(10) \# 2$ & $70.65(6)$ & $\mathrm{O}(3)-\mathrm{Mo}(3)-\mathrm{O}(6) \# 2$ & $104.41(9)$ \\
\hline $\mathrm{O}(3)-\mathrm{Mo}(3)-\mathrm{O}(8) \# 2$ & $102.15(9)$ & $\mathrm{O}(6) \# 2-\mathrm{Mo}(3)-\mathrm{O}(8) \# 2$ & $96.64(8)$ \\
\hline $\mathrm{O}(3)-\mathrm{Mo}(3)-\mathrm{O}(10)$ & $100.70(9)$ & $\mathrm{O}(6) \# 2-\mathrm{Mo}(3)-\mathrm{O}(10)$ & $95.72(8)$ \\
\hline $\mathrm{O}(8) \# 2-\mathrm{Mo}(3)-\mathrm{O}(10)$ & $150.34(7)$ & $\mathrm{O}(3)-\mathrm{Mo}(3)-\mathrm{O}(4)$ & $99.41(8)$ \\
\hline $\mathrm{O}(6) \# 2-\mathrm{Mo}(3)-\mathrm{O}(4)$ & $156.14(8)$ & $\mathrm{O}(8) \# 2-\mathrm{Mo}(3)-\mathrm{O}(4)$ & $79.52(7)$ \\
\hline $\mathrm{O}(10)-\mathrm{Mo}(3)-\mathrm{O}(4)$ & $78.30(7)$ & $\mathrm{O}(3)-\mathrm{Mo}(3)-\mathrm{O}(4) \# 2$ & $175.49(8)$ \\
\hline $\mathrm{O}(6) \# 2-\mathrm{Mo}(3)-\mathrm{O}(4) \# 2$ & $80.10(7)$ & $\mathrm{O}(8) \# 2-\mathrm{Mo}(3)-\mathrm{O}(4) \# 2$ & $77.12(6)$ \\
\hline $\mathrm{O}(10)-\mathrm{Mo}(3)-\mathrm{O}(4) \# 2$ & $78.60(7)$ & $\mathrm{O}(4)-\mathrm{Mo}(3)-\mathrm{O}(4) \# 2$ & $76.08(7)$ \\
\hline $\mathrm{O}(13)-\mathrm{Mo}(4)-\mathrm{O}(12)$ & $103.95(10)$ & $\mathrm{O}(13)-\mathrm{Mo}(4)-\mathrm{O}(11)$ & $99.77(9)$ \\
\hline $\mathrm{O}(12)-\mathrm{Mo}(4)-\mathrm{O}(11)$ & $100.15(8)$ & $\mathrm{O}(13)-\mathrm{Mo}(4)-\mathrm{O}(10)$ & $102.30(9)$ \\
\hline $\mathrm{O}(12)-\mathrm{Mo}(4)-\mathrm{O}(10)$ & $99.78(8)$ & $\mathrm{O}(11)-\mathrm{Mo}(4)-\mathrm{O}(10)$ & $145.56(7)$ \\
\hline $\mathrm{O}(13)-\mathrm{Mo}(4)-\mathrm{O}(4)$ & $159.44(8)$ & $\mathrm{O}(12)-\mathrm{Mo}(4)-\mathrm{O}(4)$ & $96.61(8)$ \\
\hline $\mathrm{O}(11)-\mathrm{Mo}(4)-\mathrm{O}(4)$ & $76.54(7)$ & $\mathrm{O}(10)-\mathrm{Mo}(4)-\mathrm{O}(4)$ & $73.49(7)$ \\
\hline $\mathrm{O}(13)-\mathrm{Mo}(4)-\mathrm{O}(8)$ & $88.18(8)$ & $\mathrm{O}(12)-\mathrm{Mo}(4)-\mathrm{O}(8)$ & $166.83(8)$ \\
\hline $\mathrm{O}(11)-\mathrm{Mo}(4)-\mathrm{O}(8)$ & $82.47(7)$ & $\mathrm{O}(10)-\mathrm{Mo}(4)-\mathrm{O}(8)$ & $72.21(7)$ \\
\hline $\mathrm{O}(4)-\mathrm{Mo}(4)-\mathrm{O}(8)$ & $71.32(6)$ & & \\
\hline
\end{tabular}

Symmetry codes for 3 : \#1-x+2, -y+1, -z+2; \#2x-1, y, z; \#3x+1,y, z; \#4x,y-1, z; \#5x,y+1, z

Table S4. Selected bond distances $(\AA)$ and angles $\left({ }^{\circ}\right)$ for 4 .

\begin{tabular}{llll}
\hline $\mathrm{Cu}(1)-\mathrm{N}(2)$ & $2.010(4)$ & $\mathrm{Cu}(1)-\mathrm{N}(8)$ & $2.035(4)$ \\
$\mathrm{Cu}(1)-\mathrm{O}(10)$ & $2.433(3)$ & $\mathrm{Cu}(2)-\mathrm{N}(6) \# 2$ & $1.986(4)$ \\
$\mathrm{Cu}(2)-\mathrm{N}(11)$ & $2.021(3)$ & & \\
$\mathrm{Mo}(1)-\mathrm{O}(5)$ & $1.683(3)$ & $\mathrm{Mo}(1)-\mathrm{O}(3)$ & $1.748(3)$ \\
$\mathrm{Mo}(1)-\mathrm{O}(7)$ & $1.935(3)$ & $\mathrm{Mo}(1)-\mathrm{O}(6)$ & $1.959(3)$ \\
$\mathrm{Mo}(1)-\mathrm{O}(4) \# 5$ & $2.204(3)$ & $\mathrm{Mo}(1)-\mathrm{O}(4)$ & $2.348(3)$
\end{tabular}




\begin{tabular}{|c|c|c|c|}
\hline Mo(1)-Mo(4) & $3.1979(5)$ & $\mathrm{Mo}(2)-\mathrm{O}(8)$ & $1.687(4)$ \\
\hline $\mathrm{Mo}(2)-\mathrm{O}(9)$ & $1.699(3)$ & $\mathrm{Mo}(2)-\mathrm{O}(13)$ & $1.903(3)$ \\
\hline $\mathrm{Mo}(2)-\mathrm{O}(6) \# 5$ & $2.011(3)$ & $\mathrm{Mo}(2)-\mathrm{O}(4)$ & $2.324(3)$ \\
\hline $\mathrm{Mo}(2)-\mathrm{O}(7)$ & $2.331(3)$ & $\mathrm{Mo}(3)-\mathrm{O}(2)$ & $1.691(3)$ \\
\hline $\mathrm{Mo}(3)-\mathrm{O}(1)$ & $1.717(3)$ & $\mathrm{Mo}(3)-\mathrm{O}(13)$ & $1.906(3)$ \\
\hline $\mathrm{Mo}(3)-\mathrm{O}(11) \# 5$ & $1.940(3)$ & $\mathrm{Mo}(3)-\mathrm{O}(3)$ & $2.296(3)$ \\
\hline $\mathrm{Mo}(3)-\mathrm{O}(4)$ & $2.505(3)$ & $\mathrm{Mo}(4)-\mathrm{O}(12)$ & $1.706(3)$ \\
\hline $\mathrm{Mo}(4)-\mathrm{O}(10)$ & $1.714(3)$ & $\mathrm{Mo}(4)-\mathrm{O}(11)$ & $1.888(3)$ \\
\hline $\mathrm{Mo}(4)-\mathrm{O}(7)$ & $2.005(3)$ & $\mathrm{Mo}(4)-\mathrm{O}(4) \# 5$ & $2.267(3)$ \\
\hline $\mathrm{Mo}(4)-\mathrm{O}(6) \# 5$ & $2.305(3)$ & $\mathrm{O}(4)-\mathrm{Mo}(1) \# 5$ & $2.204(3)$ \\
\hline $\mathrm{O}(4)-\mathrm{Mo}(4) \# 5$ & $2.267(3)$ & $\mathrm{O}(6)-\mathrm{Mo}(2) \# 5$ & $2.011(3)$ \\
\hline $\mathrm{O}(6)-\mathrm{Mo}(4) \# 5$ & $2.305(3)$ & $\mathrm{O}(11)-\mathrm{Mo}(3) \# 5$ & $1.940(3)$ \\
\hline $\mathrm{N}(2)-\mathrm{Cu}(1)-\mathrm{N}(8)$ & $88.62(16)$ & $\mathrm{N}(2) \# 1-\mathrm{Cu}(1)-\mathrm{N}(8) \# 1$ & $88.62(16)$ \\
\hline N(2)\#1-Cu(1)-N(8) & $91.38(16)$ & $\mathrm{N}(2)-\mathrm{Cu}(1)-\mathrm{N}(8) \# 1$ & $91.38(16)$ \\
\hline $\mathrm{N}(2)-\mathrm{Cu}(1)-\mathrm{O}(10) \# 1$ & $86.26(14)$ & $\mathrm{N}(2) \# 1-\mathrm{Cu}(1)-\mathrm{O}(10) \# 1$ & $93.74(14)$ \\
\hline $\mathrm{N}(8)-\mathrm{Cu}(1)-\mathrm{O}(10) \# 1$ & $99.67(12)$ & $\mathrm{N}(8) \# 1-\mathrm{Cu}(1)-\mathrm{O}(10) \# 1$ & $80.33(12)$ \\
\hline $\mathrm{N}(2)-\mathrm{Cu}(1)-\mathrm{O}(10)$ & $93.74(14)$ & $\mathrm{N}(2) \# 1-\mathrm{Cu}(1)-\mathrm{O}(10)$ & $86.26(14)$ \\
\hline $\mathrm{N}(8)-\mathrm{Cu}(1)-\mathrm{O}(10)$ & $80.33(12)$ & $\mathrm{N}(8) \# 1-\mathrm{Cu}(1)-\mathrm{O}(10)$ & $99.67(12)$ \\
\hline $\mathrm{N}(6) \# 2-\mathrm{Cu}(2)-\mathrm{N}(11) \# 4$ & $88.53(15)$ & $\mathrm{N}(6) \# 3-\mathrm{Cu}(2)-\mathrm{N}(11) \# 4$ & $91.47(15)$ \\
\hline $\mathrm{N}(6) \# 2-\mathrm{Cu}(2)-\mathrm{N}(11)$ & $91.47(15)$ & $\mathrm{N}(6) \# 3-\mathrm{Cu}(2)-\mathrm{N}(11)$ & $88.53(15)$ \\
\hline $\mathrm{O}(5)-\mathrm{Mo}(1)-\mathrm{O}(7)$ & $102.19(14)$ & $\mathrm{O}(3)-\mathrm{Mo}(1)-\mathrm{O}(7)$ & $98.38(13)$ \\
\hline $\mathrm{O}(5)-\mathrm{Mo}(1)-\mathrm{O}(6)$ & $99.55(14)$ & $\mathrm{O}(3)-\mathrm{Mo}(1)-\mathrm{O}(6)$ & $97.07(13)$ \\
\hline $\mathrm{O}(7)-\mathrm{Mo}(1)-\mathrm{O}(6)$ & $148.70(11)$ & $\mathrm{O}(5)-\mathrm{Mo}(1)-\mathrm{O}(4) \# 5$ & $95.57(12)$ \\
\hline $\mathrm{O}(3)-\mathrm{Mo}(1)-\mathrm{O}(4) \# 5$ & $158.66(11)$ & $\mathrm{O}(7)-\mathrm{Mo}(1)-\mathrm{O}(4) \# 5$ & $78.10(11)$ \\
\hline $\mathrm{O}(6)-\mathrm{Mo}(1)-\mathrm{O}(4) \# 5$ & $77.63(11)$ & $\mathrm{O}(5)-\mathrm{Mo}(1)-\mathrm{O}(4)$ & $171.17(12)$ \\
\hline $\mathrm{O}(3)-\mathrm{Mo}(1)-\mathrm{O}(4)$ & $82.95(11)$ & $\mathrm{O}(7)-\mathrm{Mo}(1)-\mathrm{O}(4)$ & $77.75(10)$ \\
\hline $\mathrm{O}(6)-\mathrm{Mo}(1)-\mathrm{O}(4)$ & $77.35(10)$ & $\mathrm{O}(4) \# 5-\mathrm{Mo}(1)-\mathrm{O}(4)$ & $75.73(11)$ \\
\hline $\mathrm{O}(5)-\mathrm{Mo}(1)-\mathrm{Mo}(4)$ & $89.02(11)$ & $\mathrm{O}(3)-\mathrm{Mo}(1)-\mathrm{Mo}(4)$ & $134.86(10)$ \\
\hline $\mathrm{O}(8)-\mathrm{Mo}(2)-\mathrm{O}(9)$ & $104.7(2)$ & $\mathrm{O}(8)-\mathrm{Mo}(2)-\mathrm{O}(13)$ & $102.07(16)$ \\
\hline
\end{tabular}




\begin{tabular}{|c|c|c|c|}
\hline $\mathrm{O}(9)-\mathrm{Mo}(2)-\mathrm{O}(13)$ & $102.67(16)$ & $\mathrm{O}(8)-\mathrm{Mo}(2)-\mathrm{O}(6) \# 5$ & $99.37(16)$ \\
\hline $\mathrm{O}(9)-\mathrm{Mo}(2)-\mathrm{O}(6) \# 5$ & $96.18(15)$ & $\mathrm{O}(13)-\mathrm{Mo}(2)-\mathrm{O}(6) \# 5$ & $146.64(12)$ \\
\hline $\mathrm{O}(8)-\mathrm{Mo}(2)-\mathrm{O}(4)$ & $160.20(17)$ & $\mathrm{O}(9)-\mathrm{Mo}(2)-\mathrm{O}(4)$ & $94.62(15)$ \\
\hline $\mathrm{O}(13)-\mathrm{Mo}(2)-\mathrm{O}(4)$ & $77.39(11)$ & $\mathrm{O}(6) \# 5-\mathrm{Mo}(2)-\mathrm{O}(4)$ & $73.84(10)$ \\
\hline $\mathrm{O}(8)-\mathrm{Mo}(2)-\mathrm{O}(7)$ & $89.08(17)$ & $\mathrm{O}(9)-\mathrm{Mo}(2)-\mathrm{O}(7)$ & $162.97(15)$ \\
\hline $\mathrm{O}(13)-\mathrm{Mo}(2)-\mathrm{O}(7)$ & $83.72(11)$ & $\mathrm{O}(6) \# 5-\mathrm{Mo}(2)-\mathrm{O}(7)$ & $71.32(10)$ \\
\hline $\mathrm{O}(4)-\mathrm{Mo}(2)-\mathrm{O}(7)$ & 71.14(9) & $\mathrm{O}(2)-\mathrm{Mo}(3)-\mathrm{O}(1)$ & $104.22(16)$ \\
\hline $\mathrm{O}(2)-\mathrm{Mo}(3)-\mathrm{O}(13)$ & $99.60(16)$ & $\mathrm{O}(1)-\mathrm{Mo}(3)-\mathrm{O}(13)$ & $105.64(15)$ \\
\hline $\mathrm{O}(2)-\mathrm{Mo}(3)-\mathrm{O}(11) \# 5$ & $96.74(17)$ & $\mathrm{O}(1)-\mathrm{Mo}(3)-\mathrm{O}(11) \# 5$ & $102.64(15)$ \\
\hline $\mathrm{O}(13)-\mathrm{Mo}(3)-\mathrm{O}(11) \# 5$ & $142.52(12)$ & $\mathrm{O}(2)-\mathrm{Mo}(3)-\mathrm{O}(3)$ & $168.03(14)$ \\
\hline $\mathrm{O}(1)-\mathrm{Mo}(3)-\mathrm{O}(3)$ & $87.44(12)$ & $\mathrm{O}(13)-\mathrm{Mo}(3)-\mathrm{O}(3)$ & $79.46(12)$ \\
\hline $\mathrm{O}(11) \# 5-\mathrm{Mo}(3)-\mathrm{O}(3)$ & $77.74(12)$ & $\mathrm{O}(2)-\mathrm{Mo}(3)-\mathrm{O}(4)$ & $98.52(13)$ \\
\hline $\mathrm{O}(1)-\mathrm{Mo}(3)-\mathrm{O}(4)$ & $157.09(12)$ & $\mathrm{O}(13)-\mathrm{Mo}(3)-\mathrm{O}(4)$ & $72.82(11)$ \\
\hline $\mathrm{O}(11) \# 5-\mathrm{Mo}(3)-\mathrm{O}(4)$ & $71.53(11)$ & $\mathrm{O}(3)-\mathrm{Mo}(3)-\mathrm{O}(4)$ & $69.72(9)$ \\
\hline $\mathrm{O}(12)-\mathrm{Mo}(4)-\mathrm{O}(10)$ & $104.81(17)$ & $\mathrm{O}(12)-\mathrm{Mo}(4)-\mathrm{O}(11)$ & $100.72(15)$ \\
\hline $\mathrm{O}(10)-\mathrm{Mo}(4)-\mathrm{O}(11)$ & $103.68(15)$ & $\mathrm{O}(12)-\mathrm{Mo}(4)-\mathrm{O}(7)$ & $98.88(15)$ \\
\hline $\mathrm{O}(10)-\mathrm{Mo}(4)-\mathrm{O}(7)$ & $94.17(13)$ & $\mathrm{O}(11)-\mathrm{Mo}(4)-\mathrm{O}(7)$ & $148.98(12)$ \\
\hline $\mathrm{O}(12)-\mathrm{Mo}(4)-\mathrm{O}(4) \# 5$ & $160.29(14)$ & $\mathrm{O}(10)-\mathrm{Mo}(4)-\mathrm{O}(4) \# 5$ & $94.46(14)$ \\
\hline $\mathrm{O}(11)-\mathrm{Mo}(4)-\mathrm{O}(4) \# 5$ & $78.25(11)$ & $\mathrm{O}(7)-\mathrm{Mo}(4)-\mathrm{O}(4) \# 5$ & $75.22(11)$ \\
\hline $\mathrm{O}(12)-\mathrm{Mo}(4)-\mathrm{O}(6) \# 5$ & $87.64(14)$ & $\mathrm{O}(10)-\mathrm{Mo}(4)-\mathrm{O}(6) \# 5$ & $162.89(13)$ \\
\hline $\mathrm{O}(11)-\mathrm{Mo}(4)-\mathrm{O}(6) \# 5$ & $85.03(11)$ & $\mathrm{O}(7)-\mathrm{Mo}(4)-\mathrm{O}(6) \# 5$ & $71.99(10)$ \\
\hline $\mathrm{O}(4) \# 5-\mathrm{Mo}(4)-\mathrm{O}(6) \# 5$ & $72.65(10)$ & $\mathrm{Mo}(1)-\mathrm{O}(3)-\mathrm{Mo}(3)$ & $116.63(13)$ \\
\hline $\mathrm{Mo}(1) \# 5-\mathrm{O}(4)-\mathrm{Mo}(4) \# 5$ & $91.31(10)$ & $\mathrm{Mo}(1) \# 5-\mathrm{O}(4)-\mathrm{Mo}(2)$ & $91.64(10)$ \\
\hline $\mathrm{Mo}(4) \# 5-\mathrm{O}(4)-\mathrm{Mo}(2)$ & $163.00(13)$ & $\mathrm{Mo}(1) \# 5-\mathrm{O}(4)-\mathrm{Mo}(1)$ & $104.27(11)$ \\
\hline $\mathrm{Mo}(4) \# 5-\mathrm{O}(4)-\mathrm{Mo}(1)$ & $97.89(10)$ & $\mathrm{Mo}(2)-\mathrm{O}(4)-\mathrm{Mo}(1)$ & $97.59(10)$ \\
\hline $\mathrm{Mo}(1) \# 5-\mathrm{O}(4)-\mathrm{Mo}(3)$ & $165.06(12)$ & $\mathrm{Mo}(4) \# 5-\mathrm{O}(4)-\mathrm{Mo}(3)$ & $87.15(9)$ \\
\hline $\mathrm{Mo}(2)-\mathrm{O}(4)-\mathrm{Mo}(3)$ & $85.70(9)$ & $\mathrm{Mo}(1)-\mathrm{O}(4)-\mathrm{Mo}(3)$ & $90.66(9)$ \\
\hline $\mathrm{Mo}(1)-\mathrm{O}(6)-\mathrm{Mo}(2) \# 5$ & $109.79(13)$ & $\mathrm{Mo}(1)-\mathrm{O}(6)-\mathrm{Mo}(4) \# 5$ & $109.19(12)$ \\
\hline $\mathrm{Mo}(2) \# 5-\mathrm{O}(6)-\mathrm{Mo}(4) \# 5$ & $104.69(12)$ & $\mathrm{Mo}(1)-\mathrm{O}(7)-\mathrm{Mo}(4)$ & $108.51(13)$ \\
\hline $\mathrm{Mo}(1)-\mathrm{O}(7)-\mathrm{Mo}(2)$ & $110.64(12)$ & $\mathrm{Mo}(4)-\mathrm{O}(7)-\mathrm{Mo}(2)$ & $103.97(11)$ \\
\hline
\end{tabular}




\begin{tabular}{llll}
$\mathrm{Mo}(4)-\mathrm{O}(10)-\mathrm{Cu}(1)$ & $156.4(2)$ & $\mathrm{Mo}(4)-\mathrm{O}(11)-\mathrm{Mo}(3) \# 5$ & $118.74(15)$ \\
$\mathrm{Mo}(2)-\mathrm{O}(13)-\mathrm{Mo}(3)$ & $119.32(16)$ & $\mathrm{O}(5)-\mathrm{Mo}(1)-\mathrm{O}(3)$ & $105.72(14)$ \\
\hline
\end{tabular}

Symmetry codes for 4: \#1 -x+2, -y+1, -z+1; \#2-x+3,-y+2, -z+1; \#3 x-1, y, z-1; \#4-x+2, -y+2, $-\mathrm{z} ; \# 5-\mathrm{x}+2,-\mathrm{y},-\mathrm{z}+1 ; \# 6 \mathrm{x}+1, \mathrm{y}, \mathrm{z}+1$

Table S5. Selected bond distances $(\AA)$ and angles $\left({ }^{\circ}\right)$ for 5.

\begin{tabular}{|c|c|c|c|}
\hline $\mathrm{Mo}(1)-\mathrm{O}(3)$ & $1.696(2)$ & $\mathrm{Mo}(1)-\mathrm{O}(1)$ & $1.707(2)$ \\
\hline $\mathrm{Mo}(1)-\mathrm{O}(2)$ & $1.8957(19)$ & $\mathrm{Mo}(1)-\mathrm{O}(9) \# 1$ & $1.9984(18)$ \\
\hline $\mathrm{Mo}(1)-\mathrm{O}(8)$ & $2.2975(19)$ & $\operatorname{Mo}(1)-\mathrm{O}(11)$ & $2.3386(18)$ \\
\hline $\mathrm{Mo}(2)-\mathrm{O}(4)$ & $1.682(2)$ & $\mathrm{Mo}(2)-\mathrm{O}(10)$ & $1.7488(19)$ \\
\hline $\mathrm{Mo}(2)-\mathrm{O}(8)$ & $1.9572(18)$ & $\mathrm{Mo}(2)-\mathrm{O}(9)$ & $1.9590(18)$ \\
\hline $\mathrm{Mo}(2)-\mathrm{O}(11) \# 1$ & $2.1552(18)$ & $\mathrm{Mo}(2)-\mathrm{O}(11)$ & $2.3454(18)$ \\
\hline $\operatorname{Mo}(2)-\operatorname{Mo}(3)$ & $3.2054(4)$ & $\mathrm{Mo}(3)-\mathrm{O}(7)$ & $1.699(2)$ \\
\hline $\mathrm{Mo}(3)-\mathrm{O}(5)$ & $1.703(2)$ & $\mathrm{Mo}(3)-\mathrm{O}(6)$ & $1.8943(19)$ \\
\hline $\mathrm{Mo}(3)-\mathrm{O}(8)$ & $1.9958(18)$ & $\mathrm{Mo}(3)-\mathrm{O}(11) \# 1$ & $2.3039(18)$ \\
\hline $\mathrm{Mo}(3)-\mathrm{O}(9) \# 1$ & $2.3132(19)$ & $\mathrm{Mo}(4)-\mathrm{O}(13)$ & $1.707(2)$ \\
\hline $\mathrm{Mo}(4)-\mathrm{O}(12)$ & $1.708(2)$ & $\mathrm{Mo}(4)-\mathrm{O}(2)$ & $1.9226(19)$ \\
\hline $\mathrm{Mo}(4)-\mathrm{O}(6) \# 1$ & $1.929(2)$ & $\mathrm{Mo}(4)-\mathrm{O}(10)$ & $2.275(2)$ \\
\hline $\mathrm{Mo}(4)-\mathrm{O}(11)$ & $2.4575(18)$ & $\operatorname{Ag}(1)-\mathrm{N}(7)$ & $2.174(3)$ \\
\hline $\operatorname{Ag}(1)-N(1)$ & $2.181(3)$ & $\operatorname{Ag}(1)-\mathrm{O}(7)$ & $2.589(2)$ \\
\hline $\operatorname{Ag}(2)-\mathrm{N}(12)$ & $2.157(3)$ & $\operatorname{Ag}(2)-\mathrm{N}(5)$ & $2.176(2)$ \\
\hline $\operatorname{Ag}(2)-\operatorname{Ag}(2) \# 2$ & $2.8195(6)$ & & \\
\hline $\mathrm{O}(3)-\mathrm{Mo}(1)-\mathrm{O}(1)$ & $105.28(11)$ & $\mathrm{O}(3)-\mathrm{Mo}(1)-\mathrm{O}(2)$ & $101.40(10)$ \\
\hline $\mathrm{O}(1)-\mathrm{Mo}(1)-\mathrm{O}(2)$ & $100.46(9)$ & $\mathrm{O}(3)-\mathrm{Mo}(1)-\mathrm{O}(9) \# 1$ & $100.30(9)$ \\
\hline $\mathrm{O}(1)-\mathrm{Mo}(1)-\mathrm{O}(9) \# 1$ & $97.19(9)$ & $\mathrm{O}(2)-\mathrm{Mo}(1)-\mathrm{O}(9) \# 1$ & $147.19(8)$ \\
\hline $\mathrm{O}(3)-\mathrm{Mo}(1)-\mathrm{O}(8)$ & $89.67(9)$ & $\mathrm{O}(1)-\mathrm{Mo}(1)-\mathrm{O}(8)$ & $163.26(9)$ \\
\hline $\mathrm{O}(2)-\mathrm{Mo}(1)-\mathrm{O}(8)$ & $83.52(7)$ & $\mathrm{O}(9) \# 1-\mathrm{Mo}(1)-\mathrm{O}(8)$ & $72.28(7)$ \\
\hline $\mathrm{O}(3)-\mathrm{Mo}(1)-\mathrm{O}(11)$ & $160.88(9)$ & $\mathrm{O}(1)-\mathrm{Mo}(1)-\mathrm{O}(11)$ & $93.56(9)$ \\
\hline $\mathrm{O}(2)-\mathrm{Mo}(1)-\mathrm{O}(11)$ & $77.85(7)$ & $\mathrm{O}(9) \# 1-\mathrm{Mo}(1)-\mathrm{O}(11)$ & $73.63(7)$ \\
\hline $\mathrm{O}(8)-\mathrm{Mo}(1)-\mathrm{O}(11)$ & $71.23(6)$ & $\mathrm{O}(4)-\mathrm{Mo}(2)-\mathrm{O}(10)$ & $105.53(9)$ \\
\hline
\end{tabular}




\begin{tabular}{|c|c|c|c|}
\hline $\mathrm{O}(4)-\mathrm{Mo}(2)-\mathrm{O}(8)$ & 101.07(9) & $\mathrm{O}(10)-\mathrm{Mo}(2)-\mathrm{O}(8)$ & $96.14(8)$ \\
\hline $\mathrm{O}(4)-\mathrm{Mo}(2)-\mathrm{O}(9)$ & $101.47(9)$ & $\mathrm{O}(10)-\mathrm{Mo}(2)-\mathrm{O}(9)$ & $97.02(8)$ \\
\hline $\mathrm{O}(8)-\mathrm{Mo}(2)-\mathrm{O}(9)$ & $149.72(8)$ & $\mathrm{O}(4)-\mathrm{Mo}(2)-\mathrm{O}(11) \# 1$ & $97.86(8)$ \\
\hline $\mathrm{O}(10)-\mathrm{Mo}(2)-\mathrm{O}(11) \# 1$ & $156.60(8)$ & $\mathrm{O}(8)-\mathrm{Mo}(2)-\mathrm{O}(11) \# 1$ & $78.41(7)$ \\
\hline $\mathrm{O}(9)-\mathrm{Mo}(2)-\mathrm{O}(11) \# 1$ & $78.70(7)$ & $\mathrm{O}(4)-\mathrm{Mo}(2)-\mathrm{O}(11)$ & $173.04(8)$ \\
\hline $\mathrm{O}(10)-\mathrm{Mo}(2)-\mathrm{O}(11)$ & $81.40(8)$ & $\mathrm{O}(8)-\mathrm{Mo}(2)-\mathrm{O}(11)$ & $77.15(7)$ \\
\hline $\mathrm{O}(9)-\mathrm{Mo}(2)-\mathrm{O}(11)$ & $78.03(7)$ & $\mathrm{O}(11) \# 1-\mathrm{Mo}(2)-\mathrm{O}(11)$ & $75.20(7)$ \\
\hline $\mathrm{O}(4)-\mathrm{Mo}(2)-\mathrm{Mo}(3)$ & $89.19(7)$ & $\mathrm{O}(10)-\mathrm{Mo}(2)-\mathrm{Mo}(3)$ & $132.36(6)$ \\
\hline $\mathrm{O}(8)-\mathrm{Mo}(2)-\mathrm{Mo}(3)$ & $36.22(5)$ & $\mathrm{O}(9)-\mathrm{Mo}(2)-\mathrm{Mo}(3)$ & $124.61(5)$ \\
\hline $\mathrm{O}(11) \# 1-\mathrm{Mo}(2)-\mathrm{Mo}(3)$ & $45.92(5)$ & $\mathrm{O}(11)-\mathrm{Mo}(2)-\mathrm{Mo}(3)$ & $85.48(4)$ \\
\hline $\mathrm{O}(7)-\mathrm{Mo}(3)-\mathrm{O}(5)$ & $104.79(11)$ & $\mathrm{O}(7)-\mathrm{Mo}(3)-\mathrm{O}(6)$ & $101.05(10)$ \\
\hline $\mathrm{O}(5)-\mathrm{Mo}(3)-\mathrm{O}(6)$ & $101.99(9)$ & $\mathrm{O}(7)-\mathrm{Mo}(3)-\mathrm{O}(8)$ & $100.97(9)$ \\
\hline $\mathrm{O}(5)-\mathrm{Mo}(3)-\mathrm{O}(8)$ & $94.81(9)$ & $\mathrm{O}(6)-\mathrm{Mo}(3)-\mathrm{O}(8)$ & $147.75(8)$ \\
\hline $\mathrm{O}(7)-\mathrm{Mo}(3)-\mathrm{O}(11) \# 1$ & $162.83(9)$ & $\mathrm{O}(5)-\mathrm{Mo}(3)-\mathrm{O}(11) \# 1$ & $92.12(8)$ \\
\hline $\mathrm{O}(6)-\mathrm{Mo}(3)-\mathrm{O}(11) \# 1$ & $77.85(7)$ & $\mathrm{O}(8)-\mathrm{Mo}(3)-\mathrm{O}(11) \# 1$ & $74.16(7)$ \\
\hline $\mathrm{O}(7)-\mathrm{Mo}(3)-\mathrm{O}(9) \# 1$ & $90.44(9)$ & $\mathrm{O}(5)-\mathrm{Mo}(3)-\mathrm{O}(9) \# 1$ & $161.69(8)$ \\
\hline $\mathrm{O}(6)-\mathrm{Mo}(3)-\mathrm{O}(9) \# 1$ & $84.58(7)$ & $\mathrm{O}(8)-\mathrm{Mo}(3)-\mathrm{O}(9) \# 1$ & $71.98(7)$ \\
\hline $\mathrm{O}(11) \# 1-\mathrm{Mo}(3)-\mathrm{O}(9) \# 1$ & $72.38(6)$ & $\mathrm{O}(7)-\mathrm{Mo}(3)-\mathrm{Mo}(2)$ & $136.23(8)$ \\
\hline $\mathrm{O}(5)-\mathrm{Mo}(3)-\mathrm{Mo}(2)$ & $82.12(7)$ & $\mathrm{O}(6)-\mathrm{Mo}(3)-\mathrm{Mo}(2)$ & $120.04(6)$ \\
\hline $\mathrm{O}(8)-\mathrm{Mo}(3)-\mathrm{Mo}(2)$ & $35.42(5)$ & $\mathrm{O}(11) \# 1-\mathrm{Mo}(3)-\mathrm{Mo}(2)$ & $42.22(4)$ \\
\hline $\mathrm{O}(9) \# 1-\mathrm{Mo}(3)-\mathrm{Mo}(2)$ & $79.82(4)$ & $\mathrm{O}(13)-\mathrm{Mo}(4)-\mathrm{O}(12)$ & $104.14(11)$ \\
\hline $\mathrm{O}(13)-\mathrm{Mo}(4)-\mathrm{O}(2)$ & $103.05(10)$ & $\mathrm{O}(12)-\mathrm{Mo}(4)-\mathrm{O}(2)$ & $97.58(10)$ \\
\hline $\mathrm{O}(13)-\mathrm{Mo}(4)-\mathrm{O}(6) \# 1$ & $103.03(10)$ & $\mathrm{O}(12)-\mathrm{Mo}(4)-\mathrm{O}(6) \# 1$ & $98.38(9)$ \\
\hline $\mathrm{O}(2)-\mathrm{Mo}(4)-\mathrm{O}(6) \# 1$ & $144.91(8)$ & $\mathrm{O}(13)-\mathrm{Mo}(4)-\mathrm{O}(10)$ & $92.13(9)$ \\
\hline $\mathrm{O}(12)-\mathrm{Mo}(4)-\mathrm{O}(10)$ & $163.72(9)$ & $\mathrm{O}(2)-\mathrm{Mo}(4)-\mathrm{O}(10)$ & $77.90(8)$ \\
\hline $\mathrm{O}(6) \# 1-\mathrm{Mo}(4)-\mathrm{O}(10)$ & $78.06(8)$ & $\mathrm{O}(13)-\mathrm{Mo}(4)-\mathrm{O}(11)$ & $161.81(9)$ \\
\hline $\mathrm{O}(12)-\mathrm{Mo}(4)-\mathrm{O}(11)$ & $94.05(8)$ & $\mathrm{O}(2)-\mathrm{Mo}(4)-\mathrm{O}(11)$ & $74.41(7)$ \\
\hline $\mathrm{O}(6) \# 1-\mathrm{Mo}(4)-\mathrm{O}(11)$ & $73.46(7)$ & $\mathrm{O}(10)-\mathrm{Mo}(4)-\mathrm{O}(11)$ & $69.69(6)$ \\
\hline $\mathrm{N}(7)-\operatorname{Ag}(1)-\mathrm{N}(1)$ & $153.40(11)$ & $\mathrm{N}(7)-\mathrm{Ag}(1)-\mathrm{O}(7)$ & $119.00(9)$ \\
\hline $\mathrm{N}(1)-\operatorname{Ag}(1)-\mathrm{O}(7)$ & $86.63(9)$ & & \\
\hline
\end{tabular}


Symmetry code for 5: \#1-x, $-\mathrm{y}+1,-\mathrm{z}+1 ; \# 2-\mathrm{x}+1 / 2, \mathrm{y}+1 / 2,-\mathrm{z}+3 / 2 ; \# \mathrm{x}+1 / 2,-\mathrm{y}+3 / 2, \mathrm{z}-3 / 2$; $\# 4-x+2,-y+2,-z ; \# 5-x+1 / 2, y-1 / 2,-z+3 / 2 ; \# 6 x-1 / 2,-y+3 / 2, z+3 / 2$

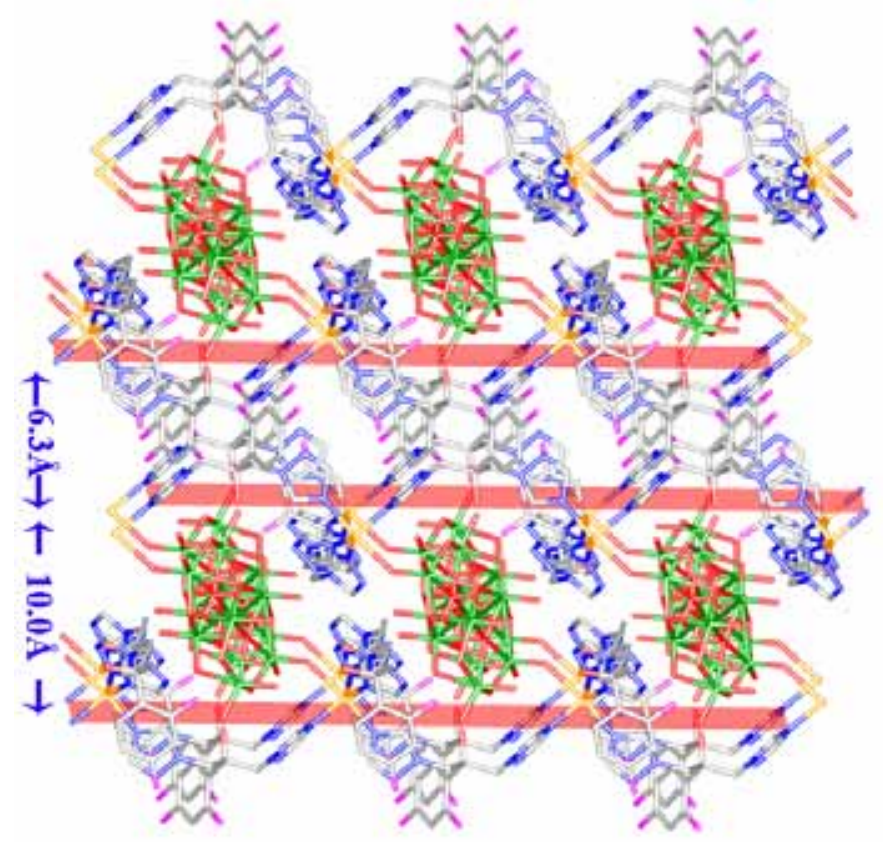

Figure S1. The distances of different sheets in $\mathbf{3}$. 

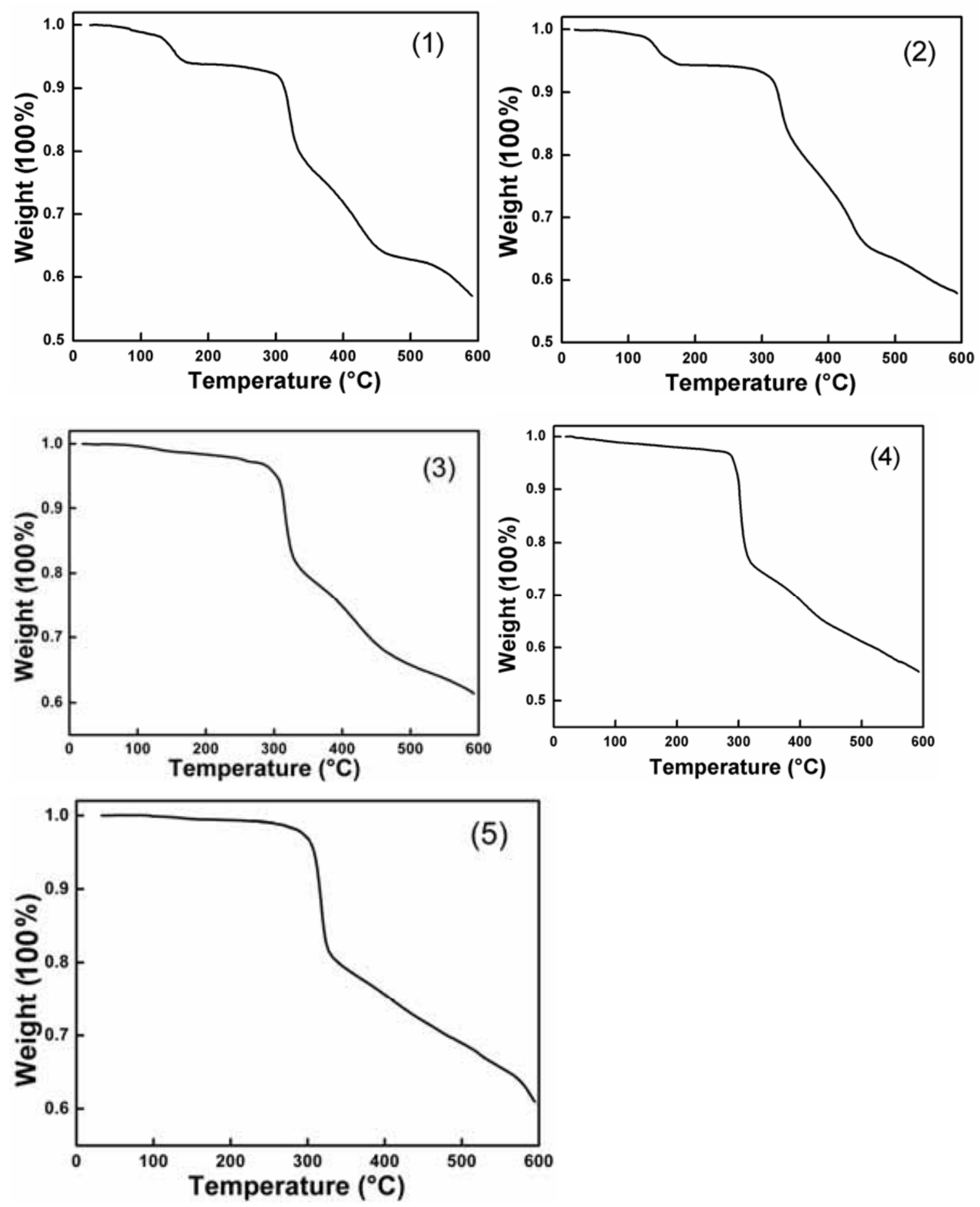

Figure S2. TG curves for compounds 1-5. 


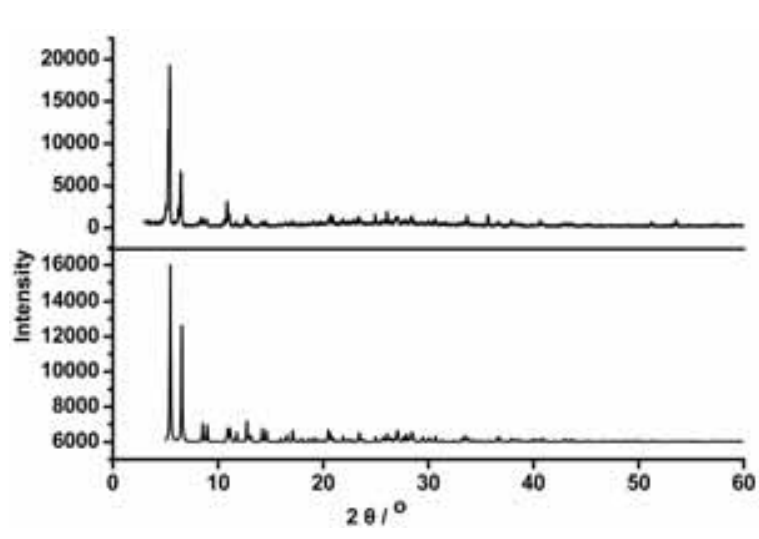

(a)

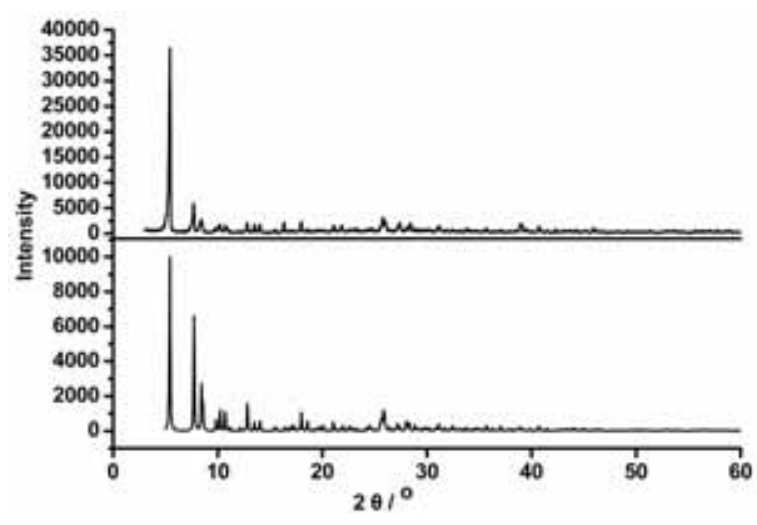

(c)

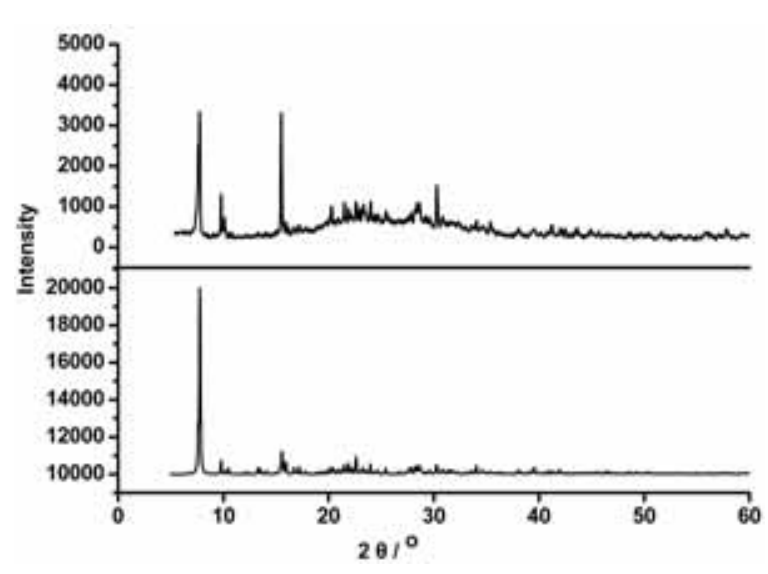

(e)

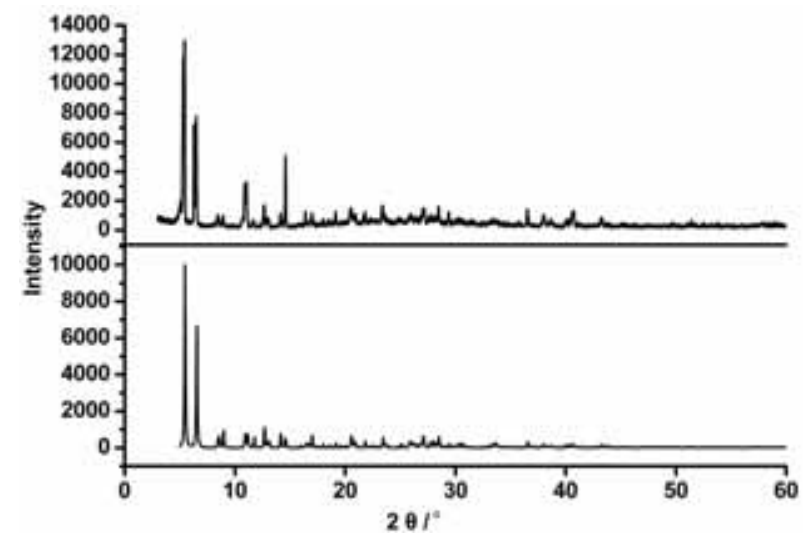

(b)

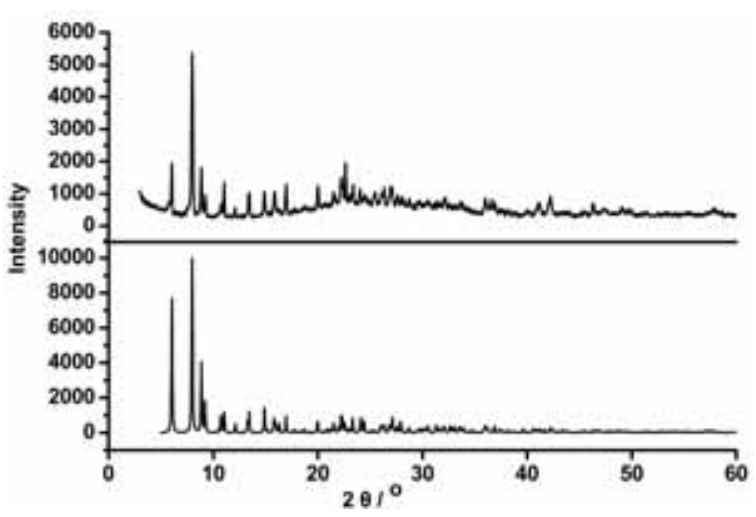

(d)

Figure S3. PXRD patterns (top) and simulated patterns (bottom) for 1 (a), 2 (b), 3 (c), 4 (d) and $\mathbf{5}(\mathrm{e})$. 
Antitumor activity studies. The antitumor activity of compounds 1-5 on SMMC-7721 cells was tested by the MTT experiment described below (Wang, X.-H.; Liu, J.-F.; Chen, Y.-G.; Liu, Q.; Liu, J.-T.; Pope, M. T. J. Chem. Soc., Dalton Trans. 2000, 1139.).

MTT, 3-[4,5-dimethylthiazol-2-yl]-2.5-diphenyltetrazolium bromide, also known as thiazolyl blue, is a dye which can accept a hydrogen atom. Surviving tumor cells are able to reduce the yellow MTT to an insoluble blue formazan in water whereas dead tumor cells do not possess this capability. The formazan product is dissolved in DMSO and then determined colorimetrically with a Microplate Reader (490 nm).

Subcultured SMMC-7721 cells were suspended in $0.25 \%$ trypsin. The cell suspension (ca. $10^{5}-10^{6}$ cells $\left.\mathrm{mL}\right)$ was added to a 96 well plate $\left(100 \mu \mathrm{L}\right.$ per well) and incubated at $37{ }^{\circ} \mathrm{C}$ in a 5\% $\mathrm{CO}_{2}$ incubator for $24 \mathrm{~h} .100 \mu \mathrm{L}$ samples containing the compounds were then added. After $72 \mathrm{~h}, 20 \mu \mathrm{L}$ MTT solution (5 $\mathrm{mg} \mathrm{mL}^{-1}$ in $0.01 \mathrm{M}$ PBS (phosphate buffer solution)) was added, and the mixture allowed to incubate for $4 \mathrm{~h}$. The supernatant was removed and DMSO $(150 \mu \mathrm{L})$ added. The resulting mixture was shaken for $10 \mathrm{~min}$ at room temperature, and colorimetric analysis was used to examine the cell survival rate and the effective cell $50 \%$ lethal concentrations $\left(\mathrm{IC}_{50}\right)$ were calculated by a statistical method.

The samples containing the title compounds were obtained by dissolving the title compounds in DMSO, autoclaving and diluting by a RPMI 1640 medium to a final concentration of 40, 20, 10,5 or $2.5 \mu \mathrm{g} \mathrm{mL} L^{-1}$.

\section{Results of antitumor activity studies}

A comparison of the antitumor activity for compounds 1-5, fcz and $\left(n-\mathrm{Bu}_{4} \mathrm{~N}\right)_{4}\left[\beta-\mathrm{Mo}_{8} \mathrm{O}_{26}\right]$ were 
made. The inhibitory effect and effective cell $50 \%$ lethal concentration $\left(\mathrm{IC}_{50}\right)$ against SMMC-7721 human cancer cell lines (see Table S6) shows that the values of $\mathrm{IC}_{50}$ range from 7.6 to $9.5 \mu \mathrm{M}$ corresponding to $\mathrm{Cu}, \mathrm{Zn}, \mathrm{Ni}, \mathrm{Co}$ and $\mathrm{Ag}$ complexes, which indicates that the five compounds exhibit high antitumor activity and the difference comes from the metal centers. The inhibitory effect of compounds 1-5 is higher than those of fcz and $\left(n-\mathrm{Bu}_{4} \mathrm{~N}\right)_{4}\left[\beta-\mathrm{Mo}_{8} \mathrm{O}_{26}\right]$. This result shows that introduction of metal complexes of fcz into the polyoxoanion surface may increase their antitumor activity, indicating that grafting of metal complexes of fcz could help the compounds to penetrate into the cells easily. The antitumor activity comes from the synergism of polyanion, transition metal ions and fcz. The in vitro antitumoral activity of 1-5 resembles the antitumoral drug of clinical practice 5-fluorouracil (Zhi, X.; Yan, L.-N.; Lin, P.; Lin, Q. Y. Chin J Bases Clin General Surg (Chin) 2004, 11, 219.) 
Table S6. Inhibitory effect of compounds $\mathbf{1 - 5}$ on tumor cells in vitro

\begin{tabular}{|c|c|c|c|}
\hline \multirow[t]{2}{*}{ Material } & \multirow[t]{2}{*}{ Dose $(\mu \mathrm{g} / \mathrm{mL})$} & \multicolumn{2}{|l|}{ SMMC-7721 } \\
\hline & & Inhibitory effect (\%) & $\mathrm{IC}_{50}{ }^{\mathrm{a}}(\mu \mathrm{M})$ \\
\hline \multirow[t]{5}{*}{ Compound 1} & 40 & 100 & 9.5 \\
\hline & 20 & 59.1 & \\
\hline & 10 & 26.7 & \\
\hline & 5 & 6.4 & \\
\hline & 2.5 & - & \\
\hline \multirow[t]{5}{*}{ Compound 2} & 40 & 99.5 & 7.9 \\
\hline & 20 & 68.5 & \\
\hline & 10 & 39.0 & \\
\hline & 5 & 25.7 & \\
\hline & 2.5 & 10.8 & \\
\hline \multirow[t]{5}{*}{ Compound $\mathbf{3}$} & 40 & 99.7 & 8.9 \\
\hline & 20 & 62.8 & \\
\hline & 10 & 36.7 & \\
\hline & 5 & 20.3 & \\
\hline & 2.5 & 7.0 & \\
\hline \multirow[t]{5}{*}{ Compound 4} & 40 & 97.8 & 7.6 \\
\hline & 20 & 51.3 & \\
\hline & 10 & 36.1 & \\
\hline & 5 & 30.3 & \\
\hline & 2.5 & - & \\
\hline \multirow[t]{5}{*}{ Compound $\mathbf{5}$} & 40 & 100 & 8.1 \\
\hline & 20 & 65.2 & \\
\hline & 10 & 33.1 & \\
\hline & 5 & 11.3 & \\
\hline & 2.5 & - & \\
\hline \multirow[t]{2}{*}{ fcz } & 40 & 4.0 & \\
\hline & 20 & - & \\
\hline \multirow[t]{4}{*}{$\left(\mathrm{n}-\mathrm{Bu}_{4} \mathrm{~N}\right)_{4}\left[\beta-\mathrm{Mo}_{8} \mathrm{O}_{26}\right]$} & 40 & 28.6 & \\
\hline & 20 & 16.6 & \\
\hline & 10 & 8.0 & \\
\hline & 5 & - & \\
\hline 5-fluorouracil & 20 & 88.8 & 4.0 \\
\hline
\end{tabular}

